\title{
Variable maternal nutrition and growth hormone treatment in the second quarter of pregnancy in pigs alter semitendinosus muscle in adolescent progeny
}

\author{
Kathryn L. Gatford ${ }^{1} *$, Jason E. Ekert ${ }^{2} \dagger$, Karina Blackmore ${ }^{2}$, Miles J. De Blasio ${ }^{1}$, \\ Jodie M. Boyce ${ }^{3} \ddagger$, Julie A. Owens ${ }^{1}$, Roger G. Campbell ${ }^{3} \S$ and Phillip C. Owens ${ }^{2}$ \\ ${ }^{1}$ Research Centre for Physiology of Early Development, School of Molecular and Biomedical Science, \\ University of Adelaide, Adelaide 5005, Australia \\ ${ }^{2}$ Department of Obstetrics and Gynaecology, University of Adelaide, Adelaide 5005, Australia \\ ${ }^{3}$ Research and Development Unit, Bunge Meat Industries Ltd, Redlands Road, Corowa 2646, Australia
}

(Received 4 July 2002 - Revised 27 February 2003 - Accepted 13 March 2003)

\begin{abstract}
Maternal nutrition and growth hormone (GH) treatment during early- to mid-pregnancy can each alter the subsequent growth and differentiation of muscle in progeny. We have investigated the effects of varying maternal nutrition and maternal treatment with porcine (p) GH during the second quarter of pregnancy in gilts on semitendinosus muscle cross-sectional area and fibre composition of progeny, and relationships between maternal and progeny measures and progeny muscularity. Fifty-three Large White $\times$ Landrace gilts, pregnant to Large White $\times$ Duroc boars, were fed either $2.2 \mathrm{~kg}$ (about $35 \%$ ad libitum intake) or $3.0 \mathrm{~kg}$ commercial ration (13.5 MJ digestible energy, $150 \mathrm{~g}$ crude protein $(\mathrm{N} \times 6 \cdot 25) / \mathrm{kg} \mathrm{DM}) / \mathrm{d}$ and injected with 0,4 or $8 \mathrm{mg} \mathrm{pGH} / \mathrm{d}$ from day 25 to 50 of pregnancy, then all were fed $2 \cdot 2 \mathrm{~kg} / \mathrm{d}$ for the remainder of pregnancy. The higher maternal feed allowance from day 25 to 50 of pregnancy increased the densities of total and secondary fibres and the secondary:primary fibre ratio in semitendinosus muscles of their female progeny at $61 \mathrm{~d}$ of age postnatally. The densities of secondary and total muscle fibres in semitendinosus muscles of progeny were predicted by maternal weight before treatment and maternal plasma insulin-like growth factor-II during treatment. Maternal pGH treatment from day 25 to day 50 of pregnancy did not alter fibre densities, but increased the cross-sectional area of the semitendinosus muscle; this may be partially explained by increased maternal plasma glucose. Thus, maternal nutrition and pGH treatment during the second quarter of pregnancy in pigs independently alter muscle characteristics in progeny.
\end{abstract}

Pregnancy: Programming: Muscle: Pig

Maternal nutrition and other factors affecting the fetal environment cause permanent changes in, or programme, postnatal growth and body composition in multiple species, including human subjects (Barker, 1998; Martorell et al. 2001), rats, pigs (Dwyer et al. 1994) and sheep (Greenwood et al. 1995). While few intra-uterine programming mechanisms have been identified, it is proposed that the environment in which critical developmental processes occur permanently determines phenotype (Lucas, 1991). Programming of postnatal growth and composition by an adverse intra-uterine environment is associated with increased risk of adult disease (Barker, 1998). We have investigated in pigs the effects on postnatal skeletal muscle structure and composition of manipulating the maternal, and hence fetal, environment during pregnancy at a critical stage of fetal muscle development.
In pigs, primary muscle fibres (peripheral myofibres, axial nuclei) form between day 35 and 60 of gestation (term about $115 \mathrm{~d}$ ), whilst secondary fibres (axial myofibres, peripheral nuclei) form between day 54 and 90 of gestation (Ashmore et al. 1973; Wigmore \& Stickland, 1983). Maternal undernutrition during the period of secondary muscle fibre development in the fetus reduces the numbers of total and secondary muscle fibres in pigs (Dwyer et al. 1994), as also occurs in guinea-pigs (Ward \& Stickland, 1991; Dwyer et al. 1995) and rats (Howells et al. 1978; Bedi et al. 1982; Wilson et al. 1988). In mature sows, maternal undernutrition prior to the period of secondary muscle fibre development in the fetus also reduces the number of secondary muscle fibres in their progeny, and the effect of maternal nutrition on muscle fibre numbers is seen in small but not large littermates (Dwyer

\footnotetext{
Abbreviations: GH, growth hormone; IGF, insulin-like growth factor; p, porcine.

* Corresponding author: Dr Kathryn L. Gatford, fax +61 88303 3356, email kathy.gatford@adelaide.edu.au

$\dagger$ Present address: California Regional Primate Research Center, University of California, Davis, CA, USA.

$¥$ Present address: Tamworth Centre for Crop Improvement, NSW Agriculture, Tamworth, NSW, 2340, Australia.

$\S$ Present address: Ausgene, P. O. Box 427, Gridley, IL, USA.
} 
et al. 1994). The effects of maternal nutrition might be expected to be more significant in the primiparous sow (gilt) where maternal growth increases the competition for available nutrients. The effect of maternal nutrition in pregnant gilts on progeny muscle development has not been reported, however. Formation of primary muscle fibres appears to be less susceptible to changes in the maternal environment, or to spontaneous restriction of fetal growth, than that of secondary fibres (Wigmore \& Stickland, 1983; Handel \& Stickland, 1987; Ward \& Stickland, 1991; Dwyer et al. 1994).

Growth hormone $(\mathrm{GH})$ is structurally similar to hormones secreted by the placenta during pregnancy (placental lactogen, placental GH variant), and treatment of pigs with GH mimics the increased insulin resistance characteristic of pregnancy (Walton \& Etherton, 1986; Gopinath \& Etherton, 1989). Fetal growth is promoted by maternal GH treatment during pregnancy in rats and in pigs (Spencer et al. 1994; Kelley et al. 1995; Sterle et al. 1995; Gatford et al. 2000), and in rats maternal GH treatment during pregnancy also programmes increased postnatal growth of progeny (Spencer et al. 1994). Programming of subsequent fetal and postnatal growth by maternal GH treatment for only part of pregnancy in pigs varies with maternal nutrition, the duration and timing of treatments and dose of $\mathrm{GH}$ administered (Kveragas et al. 1986; Kirkwood et al. 1993; Rehfeldt et al. 1993; Kelley et al. 1995). In well-fed pigs, increased muscle growth and secondary muscle fibre numbers in postnatal progeny can be programmed by maternal treatment with porcine (p) GH during early- to mid-pregnancy, before the period of secondary muscle fibre formation (Rehfeldt et al. 1993, 1996; Kelley et al. 1995). Whether maternal GH treatment also programmes progeny muscle phenotype in restrictedfed gilts is unknown.

In the present study, we have used maternal nutrition and $\mathrm{GH}$ treatment to manipulate maternal metabolism and hence the fetal environment in the pig. We have shown previously that pGH treatment of the commercially maintained (i.e. feed-restricted) gilt between days 25 and 50 of pregnancy increases fetal body weight and size, probably due to greater availability of maternal substrates and hence increased fetal nutrient supply (Gatford et al. 2000). We hypothesised that increased maternal nutrition or maternal pGH treatment during early- to mid-pregnancy in feed-restricted gilts would increase the secondary muscle fibre numbers and postnatal growth rates of their progeny. We also investigated the relationships between progeny muscle outcomes and markers of maternal and progeny growth and metabolism as indicators of the potential mechanism/s of programming of muscle by the fetal environment.

\section{Materials and methods}

\section{Animals and treatments}

The present study was designed in accordance with the Australian Code of Practice for the Care and Use of Animals for Scientific Purposes (National Health and Medical Research Council of Australia, 1997) and approved by the Animal Experimentation Ethics Committee of Bunge Meat Industries (Corowa, New South Wales, Australia). Fifty-three Large White $\times$ Landrace gilts were bred at first oestrus to crossbred (Large White $\times$ Duroc) boars. Gilts were fed $2.2 \mathrm{~kg}$ ration (13.5 MJ digestible energy and $150 \mathrm{~g}$ crude protein $(\mathrm{N} \times 6.25) / \mathrm{kg} \mathrm{DM}) / \mathrm{d}$ (about $35 \%$ ad libitum intake in this genotype) throughout pregnancy, except that from the day 25 to 50 of pregnancy, half (twenty-seven gilts) were fed $3.0 \mathrm{~kg}$ of the same ration/d. Gilts were fed the diets shown in Table 1 at 07.00 hours daily. From day 25 to 50 of pregnancy, gilts on both ration rates also received daily intramuscular injections at about 10.00 hours of $1 \mathrm{ml}$ sterile water in the neck region, containing 0,4 or $8 \mathrm{mg} \mathrm{pGH}$ (recombinant $\mathrm{pGH}$; Southern Cross Biotech Pty Ltd, Melbourne, Victoria, Australia), which delivered average dose rates of pGH across the treatment period of $0 \cdot 0,26 \cdot 7$ (SEM 0.5), or 53.1 (SEM 0.6) $\mu \mathrm{g} / \mathrm{kg}$ (six to eleven dams per group). Gilts were bled by jugular venepuncture at about 13.00 hours on day 40 of pregnancy and EDTA-plasma was stored at $-20^{\circ} \mathrm{C}$. Gilts delivered naturally at term. Within $12 \mathrm{~h}$ of birth, litter size and individual piglet body dimensions were measured and each piglet was identified by ear-tagging. Litter size was equalised by fostering piglets within treatment group at this time. A single female of median birth weight for her litter was selected at weaning $(27 \mathrm{~d}$ of age) for analysis of the effects of maternal treatments on progeny muscle development. A single gender was selected to remove confounding effects of progeny gender

Table 1. Composition of maternal diets $(\mathrm{g} / \mathrm{kg})$ during pregnancy and lactation

\begin{tabular}{|c|c|c|}
\hline Analysis* & Pregnancy diet & Lactation diet \\
\hline Digestible energy (MJ DE/kg) & 14.5 & 14.5 \\
\hline Crude protein $(\mathrm{N} \times 6.25)$ & 166 & 222 \\
\hline Fat & 55 & 49 \\
\hline Starch & 425 & 430 \\
\hline NSP & 145 & 130 \\
\hline DM & 894 & 899 \\
\hline Lysine & $8 \cdot 1$ & $11 \cdot 6$ \\
\hline Threonine & $5 \cdot 7$ & 7.9 \\
\hline Methionine & $2 \cdot 4$ & 3.5 \\
\hline Arginine & $12 \cdot 1$ & $15 \cdot 3$ \\
\hline Isoleucine & $6 \cdot 2$ & $7 \cdot 2$ \\
\hline Leucine & $12 \cdot 2$ & $15 \cdot 8$ \\
\hline Valine & $7 \cdot 9$ & $10 \cdot 2$ \\
\hline Histidine & $4 \cdot 6$ & $6 \cdot 1$ \\
\hline Phenylalanine & $7 \cdot 6$ & 9.5 \\
\hline Glycine & $9 \cdot 4$ & $14 \cdot 0$ \\
\hline Cystine & $3 \cdot 0$ & $3 \cdot 7$ \\
\hline Serine & $7 \cdot 7$ & $9 \cdot 7$ \\
\hline Alanine & $7 \cdot 8$ & $11 \cdot 0$ \\
\hline Aspartic acid & $12 \cdot 8$ & $17 \cdot 0$ \\
\hline Glutamic acid & $33 \cdot 0$ & $37 \cdot 5$ \\
\hline Vitamin and mineral premix $\dagger$ & 1.5 & 1.5 \\
\hline
\end{tabular}

$\mathrm{DE}$, digestible energy.

*From Format database, Bunge Meat Industries Ltd (Corowa, New South Wales, Australia).

†Vitamin and mineral contents (per kg mixed feed): Vitamin A $5.1 \mu \mathrm{g}$, Vitamin $D_{3} 0.05 \mu \mathrm{g}$, Vitamin $\mathrm{E} 60 \mathrm{mg}$, Vitamin $\mathrm{K} 2 \mathrm{mg}$, folic acid $0.5 \mathrm{mg}$, niacin $10 \mathrm{mg}$, calcium-D-pantothenate $5 \mathrm{mg}$, riboflavin $3.5 \mathrm{mg}$, vitamin $B_{6}$ (pyridoxine) $2 \mathrm{mg}$, vitamin $\mathrm{B}_{12}$ (cyanocobalamin) $0.02 \mathrm{mg}$, biotin $0.2 \mathrm{mg}$, selenium $0.3 \mathrm{mg}$, copper $20 \mathrm{mg}$, iron $80 \mathrm{mg}$, manganese $40 \mathrm{mg}$, zinc $75 \mathrm{mg}$, iodine $1 \mathrm{mg}$, betaine $100 \mathrm{mg}$, antioxidant (ethoxyquin, Endox, Kemin Pty Ltd, Sydney, NSW, Australia) $100 \mathrm{mg}$. 
from the analysis. Females were selected because their muscularity and live-weight gains are less than those of males and hence have a greater potential to show responses to treatments. The median-birth-weight progeny were each weighed at 27.2 (SEM 0.3), 34.2 (SEM 0.3) and 60.8 (SEM $0 \cdot 6$ ) d postnatal age. Pigs were then killed at 60.8 (SEM $0.6) \mathrm{d}$ of age by injection of $20 \mathrm{ml}$ pentobarbitone sodium (325 g/l; Lethabarb, Virbac (Aust.) Pty, Ltd, Peakhurst, New South Wales, Australia) into an ear vein. The semitendinosus muscle was immediately dissected and a section (about $15 \mathrm{~mm}$ thick) was cut perpendicular to the fibre direction midway along the muscle. A tracing was made of the section to determine its area. It was then subdivided into three to six pieces, comprising the entire area of the cross-section, so that sections of each piece would fit onto a single slide for staining. Each piece was embedded in Optimal Cutting Temperature (OCT) medium (Tissue Tek, Sakura Finetechnical Co. Ltd, Tokyo, Japan) and frozen flat in isopentane, cooled in liquid $\mathrm{N}_{2}$, placed on dry ice, and then stored at $-80^{\circ} \mathrm{C}$ prior to analysis.

\section{Analysis of maternal metabolites and hormones}

Plasma concentrations of glucose (GLUC HK, Roche Diagnostic Systems, Mannheim, Germany), urea (UREA; Roche Diagnostic Systems), non-esterified fatty acids (NEFA C; Wako Pure Chemicals, Osaka, Japan), triacylglycerol (TRIG; Roche Diagnostic Systems), lactate (LACT MPR1; Boehringer Mannheim, Mannheim, Germany) and cholesterol (CHOL; Roche Diagnostic Systems) were measured by enzymatic analysis. Plasma $\alpha$ amino-N concentrations were measured by colorimetric assay (Evans et al. 1993). Insulin was measured using a commercial radioimmunoassay (Insulin CT kit; CIS Bio International, Cedex, France). Insulin-like growth factor (IGF)-I and -II were separated from binding proteins by size-exclusion HPLC of plasma at $\mathrm{pH} 2.5$ (Owens et al. 1990). IGF-I and -II were then determined in neutralised chromatography fractions by specific radioimmunoasssay (Francis et al. 1989; Carr et al. 1995).

\section{Analysis of muscle fibres}

Tracings of muscle sections were scanned and their areas measured (n 53 progeny) using Sigma Scan Pro software (Jandel Scientific Software, San Rafael, CA, USA). Sections $(10 \mu \mathrm{m}$ thick) were cut by cryostat from each piece of the semitendinosus muscle of each pig (three to six pieces per animal, comprising the entire cross-sectional area of the muscle for each pig), and mounted on plain glass slides. Differentiation of primary and secondary fibre types (Guth \& Samaha, 1970) in porcine semitendinosus muscle was obtained by staining consecutive sections at $\mathrm{pH} 10.4$ and 4.3 for alkali-stable and acid-stable actomyosin ATPase respectively ( $n 43$ progeny). Fibres were counted in either the alkali- or acid-stained section, chosen for ease of fibre type differentiations. Each cluster of dark-stained fibres in acid-stable stained sections, or light-stained fibres in alkali-stained sections, was designated as containing one primary fibre. The total number of fibres and the number of primary fibres were counted in each field. For each slide, the total number of muscle fibres and the number of primary fibres were counted in twenty microscope fields (field area $0.4345 \times 10^{-6} \mathrm{~m}^{2}$ ), viewed at $\times 20$ magnification, which was equivalent to about $5 \%$ of the muscle area. An initial field containing a clean transverse section (approximately circular fibre cross-sections) was selected randomly, and subsequent fields were selected by moving stepwise in $1 \mathrm{~mm}$ increments. Fields containing ellipsoid fibre cross-sections, indicating a non-transverse section, were excluded, and another field chosen. Areas of large blood vessels and perimysial connective tissue were excluded from analysis. Total and primary fibres ( $n$ per field) were calculated as means of measurements made from three to six sections for each animal. Secondary muscle fibres ( $n$ per microscope field) were calculated by difference between total and primary fibre number. Mean number of total, primary and secondary fibres per $\mathrm{mm}^{2}$ (muscle fibre density) and the mean secondary fibres:primary fibres ratio were calculated for each animal.

\section{Statistics}

Results are presented as arithmetic mean values with their standard errors ( $n$ is the number of dams or progeny). Effects of maternal nutrition and maternal pGH treatment during pregnancy were assessed by two-way ANOVA. Data were transformed to achieve equivalent variance and normal distribution before ANOVA where appropriate, as indicated in the Table footnotes and Figure legends. Pairwise multiple comparisons were made using the Student-Newman-Keuls method. Associations between measurements were identified by Pearson correlation for normally distributed variables, and by Spearman's $\rho$ correlation for variables that were not normally distributed. Independent covariates were identified by forward stepwise linear regression and confirmed by multiple linear regression (SigmaStat V1; Jandel Scientific Software).

\section{Results}

\section{Maternal responses}

Maternal weight at day 25 of pregnancy (139.8 (SEM $1.3) \mathrm{kg}$ ) did not differ between treatment groups. Sows fed $3 \mathrm{~kg} / \mathrm{d}$ gained more weight from day 25 to 50 of pregnancy in absolute (Table $2, P<0.001)$ and fractional $(2 \mathrm{~kg}$ feed $/ \mathrm{d}, 11.6$ (SEM 0.7 ) \%; $3 \mathrm{~kg}$ feed/d, 17.2 (SEM $0.7 \%$; $P<0.001)$ terms than sows fed $2 \cdot 2 \mathrm{~kg} / \mathrm{d}$. Maternal pGH treatment did not affect absolute weight gain from day 25 to 50 of pregnancy (Table 2), but tended to increase fractional weight gain from day 25 to 50 of pregnancy (0 mg pGH/d, 13.8 (SEM 0.8) \%; $4 \mathrm{mg} \mathrm{pGH/d,} 15.9$ (SEM $0.8) \% ; 8 \mathrm{mg} \mathrm{pGH/d,} 13.5$ (SEM 0.9) \%; $P=0.099$ ). Sows treated with pGH lost backfat depth from day 25 to 50 of pregnancy $(P=0.002)$ and increased maternal feed level tended to decrease loss of backfat from day 25 to 50 of pregnancy $(P=0 \cdot 081$, Table 2$)$. Increased maternal nutrition increased the insulin:glucose ratio $(P=0 \cdot 044)$ and plasma cholesterol concentration $(P=0.050)$, and tended to increase the concentrations of urea $(P=0.093)$, 


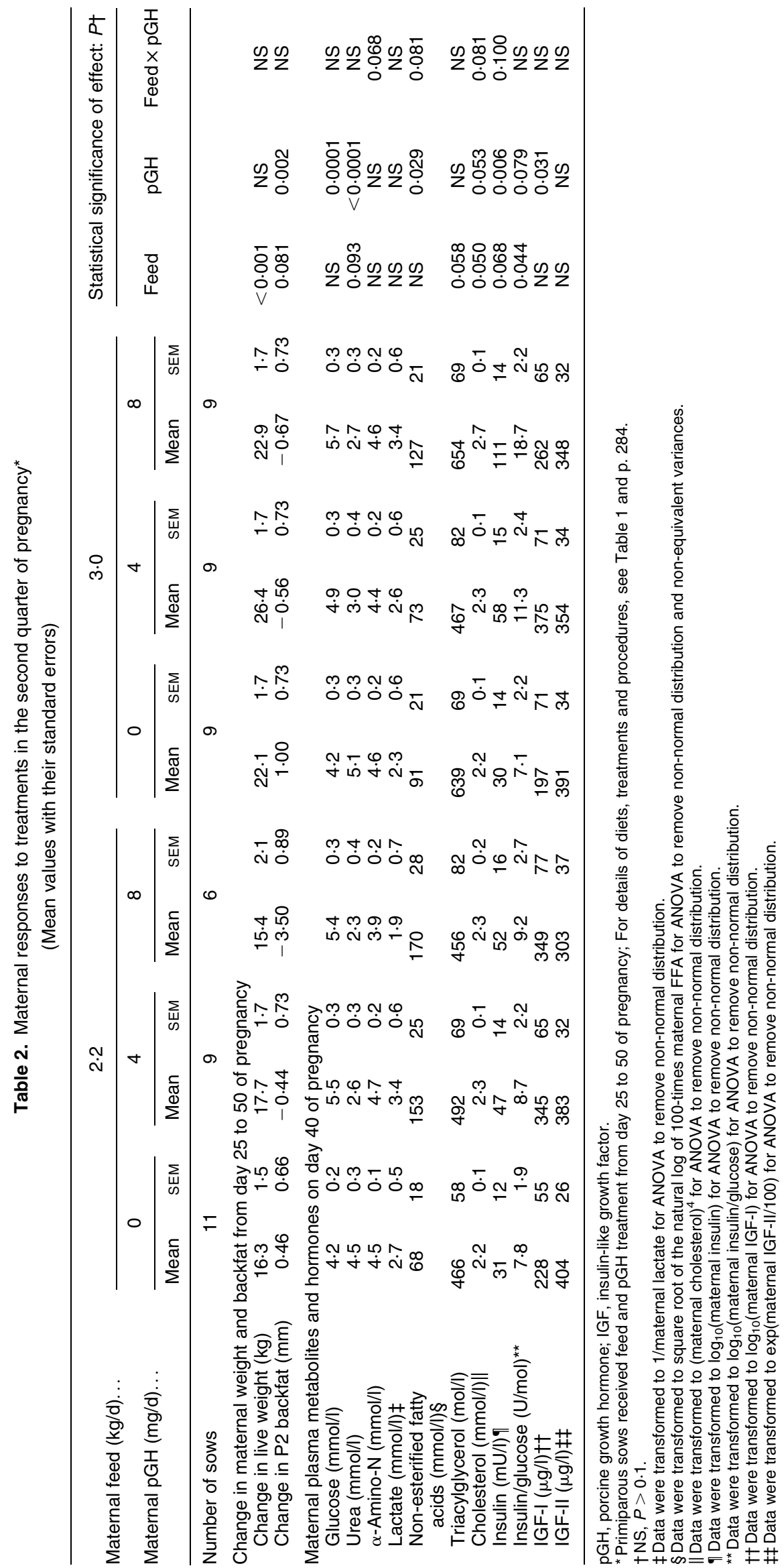


triacylglycerol $(P=0.058)$ and insulin $(P=0.068)$ in maternal plasma at day 40 of pregnancy (Table 2). Maternal pGH treatment increased the concentrations of glucose $(P<0.001)$, non-esterified fatty acids $(P=0.029)$, insulin $(P=0.006)$ and IGF-I $(P=0.031)$, and tended to increase the concentration of cholesterol $(P=0.053)$ and insulin:glucose ratio $(P=0.079)$ in maternal plasma (Table 2). Maternal pGH treatment also decreased the concentration of urea $(P<0.001)$ in maternal blood (Table 2). Maternal plasma concentrations of $\alpha$-amino-N, lactate and IGF-II were unaffected by maternal nutrition or pGH treatment (Table 2).

Overall, the absolute maternal weight-gain from day 25 to 50 of pregnancy correlated positively with maternal plasma concentrations of cholesterol $(r+0 \cdot 36, P=0.020)$ at day 40 of pregnancy. The fractional maternal weight gain from day 25 to 50 of pregnancy was also correlated positively with maternal plasma concentrations of cholesterol $(r+0.44$, $P=0.004)$ and lactate $(r+0.33, P=0.038)$. The absolute change in maternal backfat depth from day 25 to 50 of pregnancy correlated positively with the absolute $(r+0 \cdot 36$, $P=0.007)$ and fractional $(r+0.39, P=0.004)$ maternal weight gains from day 25 to 50 of pregnancy. The absolute change in maternal backfat depth from day 25 to 50 of pregnancy also correlated positively with maternal plasma concentration of urea $(r+0.43, P=0.005)$. Maternal plasma glucose concentrations correlated positively with maternal plasma concentrations of non-esterified fatty acids $(r+0.43, P=0.006)$, insulin $(r+0.53, P<0.001)$, cholesterol $(r+0 \cdot 31, \quad P=0 \cdot 045)$, IGF-I $(r+0 \cdot 33$, $P=0.034)$ and the insulin:glucose ratio $(r+0.34$, $P=0.029)$. In addition, on day 40 of pregnancy, maternal plasma concentrations of urea $(r+0.50, P=0.001)$ and lactate $(r+0.37, P=0.020)$ were correlated positively with maternal plasma IGF-II. Maternal plasma concentrations of triacyglycerol and non-esterified fatty acids were positively correlated with each other $(r+0.51$, $P=0 \cdot 001$ ), as were maternal plasma concentrations of cholesterol and lactate $(r+0 \cdot 39, P=0 \cdot 012)$.

\section{Progeny birth phenotype and postnatal growth}

Litter size ( $n 9.96$ (SEM 0.32)), live piglets born per litter ( $n$ 9.49 (SEM 0.30)) and average body weight of live newborn piglets per litter $(1.51$ (SEM 0.03$) \mathrm{kg}$ ) were unaffected by maternal treatments. Similarly, the body weight $(1.55$ (SEM 0.3) kg), length (397 (SEM 3) mm) and abdominal circumference $(257$ (SEM 3) $\mathrm{mm}$ ) of selected progeny at birth were not altered by maternal nutrition or pGH treatment. Increased maternal nutrition, but not $\mathrm{pGH}$, from day 25 to 50 of pregnancy tended to increase $(P=0 \cdot 07)$ biparietal diameter of selected progeny at birth $(2.2 \mathrm{~kg} / \mathrm{d}, 45.4$ (SEM $0.3) \mathrm{mm} ; 3.0 \mathrm{~kg} / \mathrm{d}, \quad 46.2$ (SEM 0.3$) \mathrm{mm}$ ). Higher feed intake by gilts during the second quarter of pregnancy also increased the live weight of selected progeny at $27 \mathrm{~d}$ of age $(2.2 \mathrm{~kg} / \mathrm{d}, 6.76($ SEM 0.33$) \mathrm{kg} ; 3.0 \mathrm{~kg} / \mathrm{d}, 7.70$ (SEM $0 \cdot 35) \mathrm{kg} ; \quad P=0 \cdot 040)$. Maternal nutrition did not affect weight of selected progeny at $34 \mathrm{~d}$ of age $(8.13$ (SEM $0.26) \mathrm{kg}, P=0.17)$ or at $61 \mathrm{~d}$ of age $(22.62$ (SEM 0.75$) \mathrm{kg}$, $P=0.97)$. Maternal pGH treatment from day 25 to 50 of pregnancy did not alter progeny weight at any age or growth rate for any postnatal period examined. Increased maternal nutrition from day 25 to 50 of pregnancy increased the rates of gain in body weight of selected progeny from birth to $27 \mathrm{~d}$ of age in absolute $(2.2 \mathrm{~kg} / \mathrm{d}$, 0.195 (SEM 0.011) kg/d; $3.0 \mathrm{~kg} / \mathrm{d}, 0.224$ (SEM 0.010) kg/d; $P=0.05)$ but not fractional terms $(P=0 \cdot 23)$. Absolute and fractional post-weaning growth rates were unaffected by maternal nutrition or $\mathrm{pGH}$ treatment. Growth rates averaged 0.114 (SEM 0.016) kg/d between 27 and $34 \mathrm{~d}$ of age, 0.538 (SEM 0.018$) \mathrm{kg} / \mathrm{d}$ between 34 and $61 \mathrm{~d}$ of age and 0.344 (SEM 0.010) kg/d between birth and $61 \mathrm{~d}$ of age.

Body weight of selected progeny at birth correlated positively and strongly with body length, biparietal diameter and abdominal circumference at birth $(r>+0.69$ for all, $P<0.0001$ for all). Live weights at 27 and at $34 \mathrm{~d}$ of age were also correlated positively with body weight at birth (27 d, $r+0.33, P=0.018 ; 34 \mathrm{~d}, r+0.28, P=0.045)$ and body length at birth $(27 \mathrm{~d}, r+0.30, P=0.029 ; 34 \mathrm{~d}, r$ $+0 \cdot 32, P=0 \cdot 020)$. Live weight at $61 \mathrm{~d}$ of age was not related to birth weight, but correlated positively with birth length $(r+0 \cdot 32, P=0 \cdot 021)$. Fractional growth rates from birth to $27 \mathrm{~d}$ of age $(r-0.37, P=0.007)$ and from birth to $61 \mathrm{~d}$ of age $(r-0.45, P<0.001)$ were correlated negatively with birth weight.

\section{Progeny semitendinosus muscle size and muscle fibre types}

Maternal pGH treatment during the second quarter of pregnancy increased the cross-sectional area of the semitendinosus muscle in progeny at $61 \mathrm{~d}$ of age (ANOVA $P=0.028$; Fig. 1), such that cross-sectional area was increased in progeny of sows treated with $4 \mathrm{mg} / \mathrm{d}$ relative to progeny of sows treated with $0 \mathrm{mg} \mathrm{pGH} / \mathrm{d}(P<0.05)$. However, the semitendinosus cross-sectional area relative to current live weight $\left(\mathrm{mm}^{2} / \mathrm{kg}\right)$ was not increased by maternal pGH treatment $(P=0 \cdot 1)$. Maternal pGH treatment during the second quarter of pregnancy did not affect the total number of fibres or the

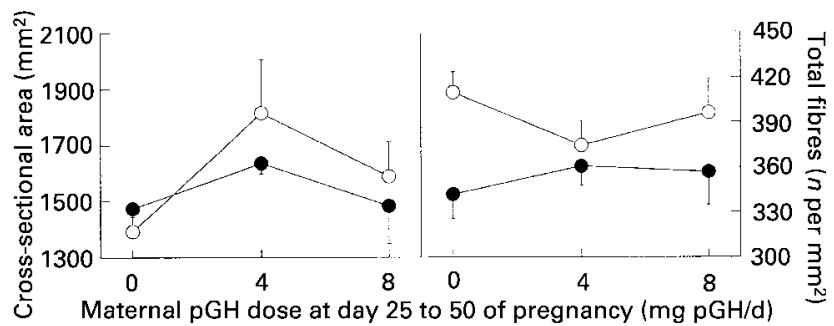

Fig. 1. Effects of maternal treatments on semitendinosus muscle size and fibre density in 61-d-old female progeny. Primiparous sows received feed and porcine $(p)$ growth hormone $(G H)$ treatments from day 25 to 50 of pregnancy, when they were fed at either $2.2(\bullet)$ or $3.0(0) \mathrm{kg} / \mathrm{d}$. For details of diets, treatments and procedures, see Table 1 and p. 284. Values are means with their standard errors shown by vertical bars. Cross-sectional area data were log-transformed for statistical analyses to remove non-equivalent variances. The cross-sectional area of semitendinosus muscle in 61-d-old progeny was increased by maternal pGH treatment $(P=0.028)$, but was not altered by maternal feed $(P=0.47)$. Semitendinosus muscle cross-sectional area was higher in progeny of sows treated with $4 \mathrm{mg} \mathrm{pGH/d}$ than in progeny of sows treated with $0 \mathrm{mg} \mathrm{pGH} / \mathrm{d}(P<0.05)$. The total number of muscle fibres per $\mathrm{mm}^{2}$ was higher $(P=0.011)$ in progeny of sows fed $3.0 \mathrm{~kg} / \mathrm{d}$ than in progeny of sows fed $2.2 \mathrm{~kg} / \mathrm{d}$ in the second quarter of pregnancy, but was not affected by maternal pGH treatment $(P=0.86)$. 


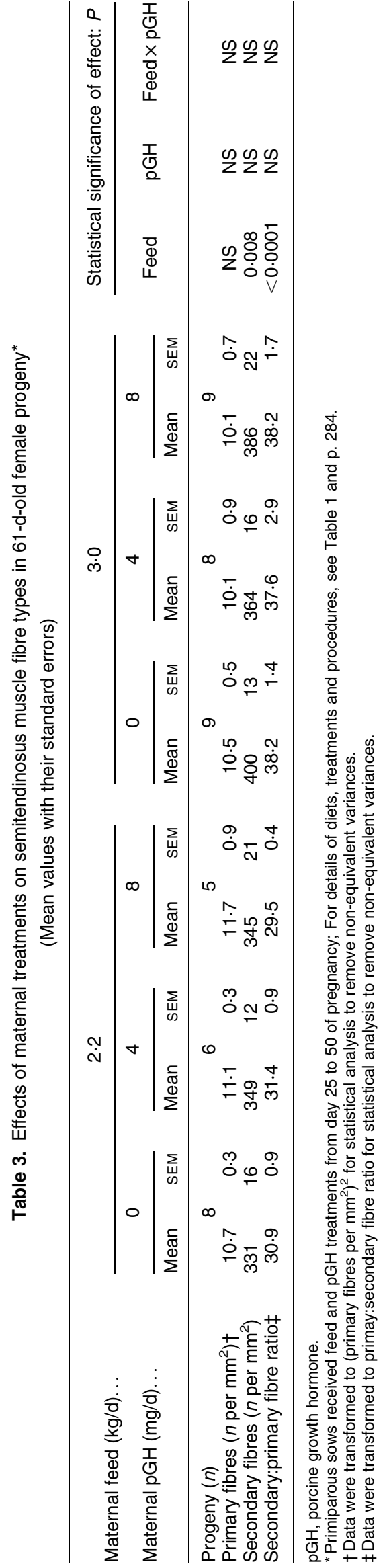

numbers of primary or secondary fibres per $\mathrm{mm}^{2}$ of muscle cross-section, nor the secondary:primary fibres ratio in semitendinosus muscle of progeny (Fig. 1, Table 3). Higher maternal feed during the second quarter of pregnancy increased $(P=0 \cdot 011)$ the total number of fibres per $\mathrm{mm}^{2}$ (Fig. 1), the number of secondary fibres per $\mathrm{mm}^{2}$ $(P=0.008)$ and the secondary:primary fibre ratio $(P<0.0001)$ in semitendinosus muscle of progeny (Table 3). Maternal feed during the second quarter of pregnancy did not alter semitendinosus cross-sectional area (Fig. 1) or the number of primary fibres per $\mathrm{mm}^{2}$ (Table 3 ).

\section{Co-variates of progeny semitendinosus muscle measurements}

Most $(60 \%)$ of the variance in cross-sectional area of semitendinosus muscle in progeny was independently predicted by current $(61 \mathrm{~d})$ progeny live weight (positive), with a small positive effect of maternal plasma glucose during treatment in pregnancy (Fig. 2). Most $(58 \%)$ of the variation in the density of primary muscle fibres $\left(n\right.$ per $\mathrm{mm}^{2}$ muscle cross-section) was independently predicted (Table 4) by current progeny live weight (negative), maternal plasma cholesterol (negative) and maternal plasma non-esterified fatty acids (positive). About onethird of the variance in secondary fibre density in progeny muscle was independently predicted (Table 4) by maternal weight on day 25 of pregnancy before treatments commenced (positive), and maternal plasma concentration of IGF-II during treatment (negative). Similarly, $44 \%$ of the variance in total density (primary plus secondary) of fibres in progeny semitendinosus muscle was independently predicted (Table 4) by maternal weight before treatments

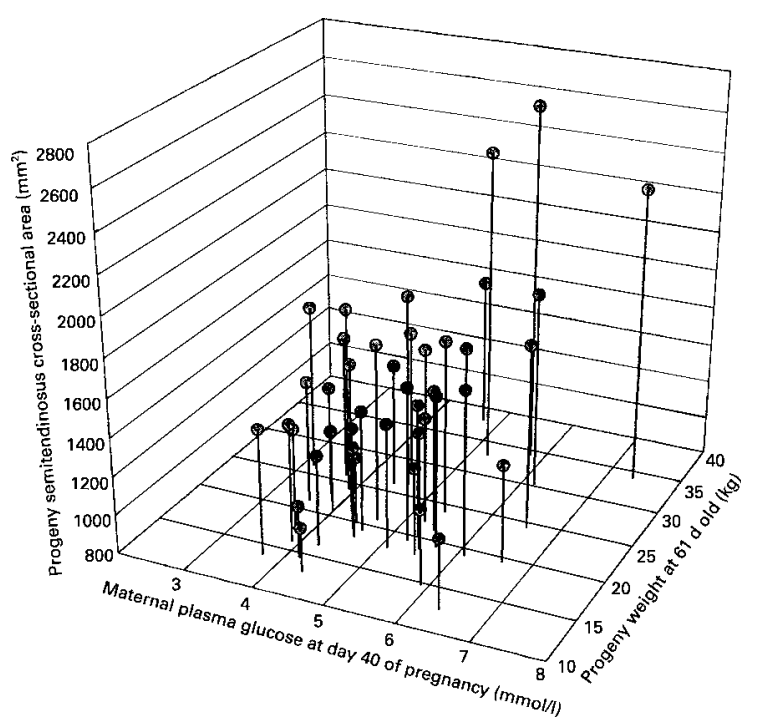

Fig. 2. Correlates of semitendinosus muscle cross-sectional area in 61-d-old progeny. For details of diets, treatments and procedures, see Table 1 and p. 284. Semitendinosus muscle cross-sectional area in 61-d-old progeny was predicted by multiple linear regression equation: $2.94+(0.394 \times$ progeny weight at $61 \mathrm{~d})+(0.734 \times$ maternal glucose at day 40 ). The forward stepwise regression gave an overall relationship of $r^{2} 0.60, P<0.0001 . \Delta r^{2}$ for progeny weight at $61 \mathrm{~d}$ was $r^{2} 0.56, P<0.0001$ and $\Delta r^{2}$ for maternal glucose at day 40 of pregnancy was $r^{2} 0.04, P=0.046$. 


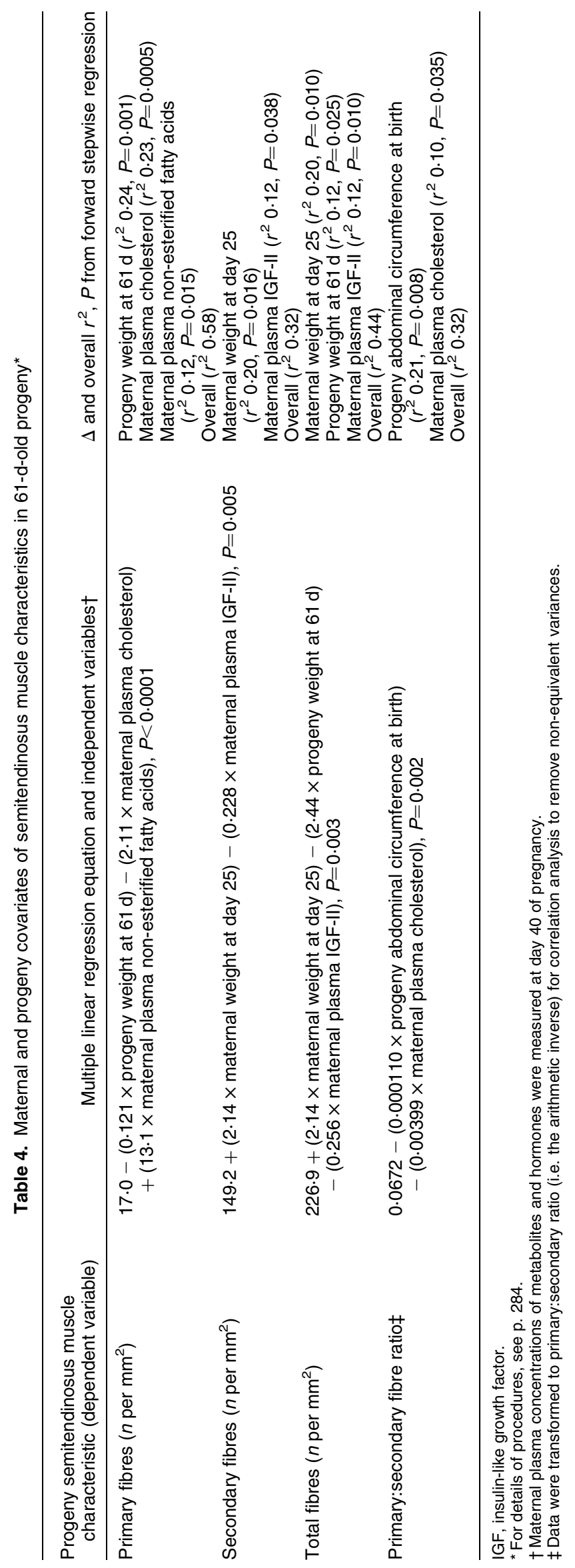


commenced (positive), maternal plasma IGF-II during treatment (negative) and current (61d) progeny live weight (negative). About one-third of the variation in the number of primary fibres:secondary fibres in progeny muscle was independently predicted (Table 4) by progeny abdominal circumference at birth (negative) and maternal plasma cholesterol during treatments (negative).

\section{Discussion}

Increased feed availability and maternal pGH treatment in the second quarter of pregnancy (from day 25 to 50) independently altered semitendinosus muscle characteristics in different ways in young female progeny postnatally. Increased availability of maternal feed, i.e. reduced nutritional restriction, during the second quarter of pregnancy increased the density of secondary muscle fibres formed in the semitendinosus muscle of progeny that were of median birth weight for their litter, and hence increased their total muscle fibre density and the secondary:primary fibres ratio. Effects of maternal nutrition on progeny muscle fibre density thus extend beyond the smallest progeny of each litter, which have previously been shown to be sensitive to increased maternal nutrition during this period of pregnancy (Dwyer et al. 1994). We have also demonstrated that progeny muscle fibre number is more sensitive to maternal nutrition than shown previously by Dwyer et al. (1994). In the present study, the increase in maternal energy intake was smaller than that given previously, we fed mothers only once per d, and we investigated progeny of gilts, which might be expected to have a greater nutrient demand for their own growth than the third parity sows used by Dwyer et al. (1994). Our present results confirm, however, that the level of maternal nutrition prior to the period of fetal secondary muscle fibre formation can programme muscle development in progeny. Because pigs with a higher secondary:primary fibres ratio in their muscles have faster growth rates and better feed-conversion efficiency during the finisher period (Dwyer et al. 1993), increased maternal nutrition during the second quarter of pregnancy in commercially managed gilts is also likely to improve the finisher performance of their progeny.

Maternal pGH treatment did not affect the fibre composition, but increased the cross-sectional area of semitendinosus muscle in progeny of restricted-fed gilts. This increase in muscle size is consistent with the findings of Kelley et al. (1995) in well-fed gilts, where maternal pGH treatment of gilts from day 28 to 40 of pregnancy increased semitendinosus muscle weight and longissimus dorsi cross-sectional area in $20 \mathrm{~kg}$ progeny. In the present study, the increase in semitendinosus muscle cross-sectional area in offspring following maternal treatment with pGH must reflect either greater numbers of fibres per muscle or an increase in non-fibre tissues such as perimysial connective tissue within muscle, since pGH treatment did not alter the density of fibres in muscle. Unlike administration of maternal $\mathrm{GH}$ earlier in pregnancy in mature sows (day 10 to 24 or 27), which has been shown to increase muscle fibre numbers and density in progeny at birth (Rehfeldt et al. 1993, 1996), maternal GH treatment of gilts in the second quarter of pregnancy did not alter muscle fibre numbers of progeny. This suggests that progeny muscle fibres are sensitive to maternal GH treatment and maternal nutrition at different times during gestation. Progeny muscle size responses to maternal pGH treatment did not vary with maternal nutrition, further suggesting that maternal GH treatment acts on progeny muscle development through a different mechanism than does maternal nutrition.

During the treatment period, increased maternal feed intake (reduced nutritional restriction) increased maternal weight gain, whilst treatment with $\mathrm{pGH}$ reduced maternal fat. The maternal metabolic responses to $\mathrm{pGH}$ treatment (increased concentrations of IGF-I, insulin, glucose and non-esterified fatty acids and decreased concentrations of urea in maternal plasma) were qualitatively similar to the increases in insulin resistance and IGF-I expression and decreases in lipogenesis and protein breakdown typical of pGH treatment of non-pregnant pigs. In non-pregnant pigs, the quantitative responses to $\mathrm{pGH}$ treatment vary with development or age, genotype, gender, nutrition and time (Owens et al. 1990; Klindt et al. 1995; Harrell et al. 1999). In previous studies in pregnant pigs maternal plasma IGF-I concentrations of about 230-260 $\mu \mathrm{g}$ (about $30-35 \mathrm{nmol} / \mathrm{l}) / 1$ were attained in response to 1 week or more of daily injections of pGH at doses of $26-33 \mu \mathrm{g} / \mathrm{kg}$ per d (Sterle et al. 1995; Gatford et al. 2000). In the present study, maternal plasma IGF-I concentrations reached about $330 \mu \mathrm{g}$ (about $45 \mathrm{nmol}$ )/ 1 after $15 \mathrm{~d}$ treatment with $\mathrm{pGH}$ at either 27 or $53 \mu \mathrm{g} / \mathrm{kg}$ per d, suggest that the maximal IGF-I response to $\mathrm{pGH}$ has been attained by a dose of about $25 \mu \mathrm{g} / \mathrm{kg}$ per $\mathrm{d}$. These results demonstrate that pregnancy increases the sensitivity of plasma IGF-I in gilts to treatment with pGH, compared with non-pregnant grower and finisher pigs, where effective dose rates are typically much greater than $50 \mu \mathrm{g} / \mathrm{kg}$ per d (Owens et al. 1990; Klindt et al. 1995; Harrell et al. 1999), and IGF-I responses continue to increase with pGH doses up to $70 \mu \mathrm{g} / \mathrm{kg}$ per d (Etherton et al. 1987). The higher basal IGF-I levels in the present study (about $210 \mu \mathrm{g}(30 \mathrm{nmol}) / \mathrm{l})$ compared with our previous study (about $75 \mu \mathrm{g}(10 \mathrm{nmol}) / 1$; Gatford et al. 2000) may be due to the $20 \%$ higher feed rate used in the present study.

Consistent with other reports, increased maternal nutrition (Dwyer et al. 1994) or pGH treatment (Kelley et al. 1995) during the second quarter of pregnancy did not increase weight of progeny at birth. We have, however, previously shown that treatment with $\mathrm{pGH}$ at doses similar to the lower dose used in the present study increases fetal body weight by about $15 \%$ at day 51 of gestation on a plane of nutrition $20 \%$ lower than that used here (Gatford et al. 2000). This implies that any gain in fetal weight in response to $\mathrm{pGH}$ (and possibly nutrition) during the treatment period is lost later in gestation due to maternal constraint of fetal growth. In the present study, increased maternal nutrition, but not pGH treatment, from day 25 to 50 of pregnancy increased progeny growth rate during lactation (birth to $27 \mathrm{~d}$ postnatally). Piglet demand is a major determinant of sow milk production, particularly in early lactation (Auldist \& King, 1995). Hence, the increased progeny growth-rate during lactation suggests that increased maternal nutrition 
in the second quarter of pregnancy increases the neonatal appetite of progeny and improves their ability to recover from maternal constraint in late gestation. Consistent with programming of appetite regulation, increased maternal nutrition at this stage of pregnancy also increases the plasma concentrations of leptin in 61-d-old progeny (Ekert et al. 2000). It is also possible that better nutrition in early pregnancy has improved maternal capacity for milk production in lactation.

The mechanisms by which nutrition and $\mathrm{pGH}$ treatment during pregnancy prior to the development of secondary fibres in the fetus programme muscle characteristics in postnatal offspring are not known. Increased feed availability to the mothers may increase the growth and diameter of primary fibres in their fetuses, which occurs during the treatment period, thereby providing a greater surface area for subsequent development of secondary muscle fibres (Wigmore \& Stickland, 1983). Alternatively, improved fetal nutrition during the treatment period might accelerate development of fetal endocrine systems, such as the IGF axis (Owens et al. 1994; Kind et al. 1995; Sterle et al. 1995), which promotes fetal muscle growth (Lok et al. 1996) and differentiation of the myoblasts that will form secondary fibres (Dwyer et al. 1994). It is also possible that the changes in muscle phenotype in adolescent progeny are secondary consequences of effects of treatments relatively early in pregnancy on developmental processes that occur either later in pregnancy or in the earlier postnatal life of progeny. Therefore, measurements of mothers and offspring were made before, during and after treatment so that covariates of muscle phenotype in adolescent progeny might be identified. These included maternal and progeny growth, as well as maternal plasma concentrations of hormones and metabolites that may influence the fetal environment. Interpretation of the plasma measurements is restricted somewhat because these were made in a specimen collected from each mother on a single occasion during treatment in pregnancy. In particular, the concentrations of insulin and the metabolites can fluctuate rapidly, so their utility as covariates is relatively weak. This is less of a problem for IGF-I and -II as stabilisation by association with IGF-binding proteins means that temporal variations in their concentrations in blood are small (Owens et al. 1991).

Neither of the maternal treatments affected the density of primary fibres ( $n$ per $\mathrm{mm}^{2}$ transverse sectional area) in progeny muscle. Most of the variation in primary fibre density could be explained by variation in the live weight of progeny at the time of collection of the muscle specimen $(24 \%)$, combined with variation in the concentrations of cholesterol $(23 \%)$ and non-esterified fatty acids $(12 \%)$ found in maternal blood during treatment in pregnancy. These independent covariates together accounted for $58 \%$ of the variation in primary fibre density in muscle. Given the strong correlations between maternal plasma cholesterol and lactate and between maternal plasma non-esterified fatty acids and glucose during the treatment period, these relationships probably do not directly reflect the mechanisms which determine primary muscle fibre density, but do suggest that the metabolic state of the mother during treatment in pregnancy is the major prospective determinant of primary muscle fibre density in postnatal progeny.

Feed availability, but not pGH treatment, in the second quarter of pregnancy increased the density of secondary fibres, the total (primary plus secondary) density of fibres and the secondary:primary fibre ratio in semitendinosus muscle of adolescent progeny. However, maternal nutrition did not alter any of the covariates of secondary or total muscle fibre density (maternal live weight at day 25 of pregnancy, maternal plasma IGF-II concentrations during treatment and progeny body-weight at $61 \mathrm{~d}$ of age), implying that these factors are not involved in the mechanism by which increased feed availability in the second quarter of pregnancy increases secondary and total fibre density in semitendinosus muscle of adolescent offspring. Although maternal nutrition increased both maternal cholesterol during pregnancy and the secondary: primary fibres ratio in postnatal progeny, maternal pGH treatment also increased maternal cholesterol but did not alter the ratio of fibre types in postnatal progeny, implying that increased maternal cholesterol is not a mechanism for the effects of these treatments on muscle fibre composition. The association between muscle fibre density and later progeny weight is consistent with higher growth potential in animals with more muscle fibres, as shown previously in older animals (Dwyer et al. 1993). The positive associations between maternal size prior to treatment, and total and secondary fibre density in progeny semitendinosus muscle at $61 \mathrm{~d}$ of age are consistent with the degree of maternal constraint of fetal growth during formation of secondary muscle fibres affecting their development, since larger gilts are likely to have more energy reserves to support fetal growth. In addition, these studies were conducted in a commercial population that has very low genetic heterogeneity, so heavier gilts are probably also slightly more mature than lighter gilts and will have slightly less nutrient demand for maternal growth during pregnancy. Nutritional manipulations that increase maternal growth in adolescent sheep compromise growth of their placenta and fetus (Wallace et al. 1996), and fetal muscle growth is reduced in conjunction with increased maternal muscle and fat deposition in the adolescent sheep (Palmer et al. 1998). The association between the concentrations of IGF-II in maternal blood at the end of the first third of pregnancy and the density of muscle fibres in adolescent progeny suggests a novel potential role for maternal IGF-II during pregnancy in an intra-uterine programming mechanism. Studies of mice that are deficient in IGF-II due to mutation of the $I g f 2$ gene show that this growth factor is essential for placental development (Graves, 1998). In addition, we recently observed that the concentrations of endogenous IGF-II in the blood of pregnant guinea-pigs are related to histological markers of placental development and transport capacity (Roberts et al. 2001), and have also shown that treatment of pregnant guinea-pigs with IGFII increases placental weight (Sohlstrom et al. 2001). Therefore it is possible that IGF-II in the maternal circulation has actions that improve the ability of the placenta to transfer nutrients to the fetus that are important for muscle development. 
Maternal pGH treatment increased both progeny semitendinosus cross-sectional area and maternal plasma glucose at day 40 of pregnancy, and maternal plasma glucose was a positive but weak covariate of semitendinosus cross-sectional area. Increased maternal glucose may partly mediate the effect of maternal pGH treatment on muscle growth, although the increase in maternal glucose in response to maternal GH treatment was not sufficient to account for the observed increase in semitendinosus cross-sectional area in progeny, suggesting that maternal pGH treatment also increases muscle cross-sectional area by glucoseindependent mechanisms. Direct infusion of glucose into pregnant gilts and examination of muscle characteristics in their progeny would clarify the role of glucose in programming of muscle.

In conclusion, maternal pGH treatment and increased nutrition during the second quarter of pregnancy in feed-restricted gilts differentially affect the size and fibre composition of progeny semitendinosus muscle. The mechanisms for programming of muscle fibre types by an altered maternal environment may involve endocrine IGF-II in the mother and require further investigation. Increased maternal plasma glucose may partially account for the increase in progeny semitendinosus cross-sectional area in response to maternal pGH treatment.

\section{Acknowledgements}

This research was supported in part by the Pig Research and Development Corporation of Australia. K.L.G. was supported initially by a Pig Research and Development Corporation Scholarship and subsequently a Peter Doherty Postdoctoral Fellowship from the National Health and Medical Research Council of Australia. The authors thank Dave Harrison for assistance with animal studies and Linda Mundy for performing the metabolite assays.

\section{References}

Ashmore CR, Addis PB \& Doerr L (1973) Development of muscle fibres in the fetal pig. J Anim Sci 36, 1088-1093.

Auldist DE \& King RH (1995) Piglets' role in determining milk production in the sow. In Manipulating Pig Production V. Proceedings of the Fifth Biennial Conference of the Australasian Pig Science Association [DP Hennessy and PD Cranwell, editors]. Canberra, Australian Capital Territory: APSA.

Barker DJP (1998) Mothers, Babies and Health in Later Life, 2nd ed., Edinburgh: Churchill Livingstone.

Bedi KS, Birzgalis AR, Mahon M, Smart JL \& Wareham AC (1982) Early life undernutrition in rats 1. Quantitative histology of skeletal muscles from underfed young and refed adult animals. Brit J Nutr 47, 417-431.

Carr JM, Owens JA, Grant PA, Walton PE, Owens PC \& Wallace JC (1995) Circulating insulin-like growth factors (IGFs), IGFbinding proteins (IGFBPs) and tissue mRNA levels of IGFBP-2 and IGFBP-4 in the ovine fetus. $J$ Endocrinol 145, $545-557$.

Dwyer CM, Fletcher JM \& Stickland NC (1993) Muscle cellularity and postnatal growth in the pig. J Anim Sci 71, 3339-3343.

Dwyer CM, Madgwick AJA, Ward SS \& Stickland NC (1995) Effect of maternal undernutrition in early gestation on the development of fetal myofibres in the guinea-pig. Reprod Fertil Dev 7, 1285-1292.

Dwyer CM, Stickland NC \& Fletcher JM (1994) The influence of maternal nutrition on muscle fiber number development in the porcine fetus and on subsequent postnatal growth. J Anim Sci 72, 911-917.

Ekert JE, Gatford KL, Luxford BG, Campbell RG \& Owens PC (2000) Leptin expression in offspring is programmed by nutrition in pregnancy. $J$ Endocrinol 165, R1-R6.

Etherton TD, Wiggins JP \& Evock CM, et al. (1987) Stimulation of pig growth performance by porcine growth hormone: Determination of the dose-response relationship. J Anim Sci 64, 433-443.

Evans PC, Ffolliott-Powell FM \& Harding JE (1993) A colorimetric assay for amino nitrogen in small volumes of blood: reaction with $\beta$-napthoquinone sulphonate. Anal Biochem 208, 334-337.

Francis GL, Owens PC, McNeil KA, Wallace JC \& Ballard FJ (1989) Purification, amino acid sequences and assay cross-reactivities of porcine insulin-like growth factor-I and -II. $J$ Endocrinol 122, 681-687.

Gatford KL, Owens JA \& Campbell RG, et al. (2000) Treatment of underfed pigs with GH throughout the second quarter of pregnancy increases fetal growth. J Endocrinol 166, 227-234.

Gopinath R \& Etherton TD (1989) Effects of porcine growth hormone on glucose metabolism of pigs: I. Acute and chronic effects on plasma glucose and insulin status. J Anim Sci 67, $682-688$.

Graves JAM (1998) Genomic imprinting, development and disease - is pre-eclampsia caused by a maternally imprinted gene? Reprod Fertil Dev 10, 23-29.

Greenwood PL, Hunt AS, Hermanson JW \& Bell AW (1998) Effects of birth weight and postnatal nutrition on neonatal sheep: I. Body growth and composition, and some aspects of energetic efficiency. J Anim Sci 76, 2354-2367.

Guth L \& Samaha FJ (1970) Procedure for the histochemical demonstration of actomyosin ATPase. Exp Neurol 28, $365-367$.

Handel SE \& Stickland NC (1987) Muscle cellularity and birth weight. Anim Prod 44, 311-317.

Harrell RJ, Thomas MJ, Boyd RD, Czerwinski SM, Steele NC \& Bauman DE (1999) Ontogenic maturation of the somatotropin/ insulin-like growth factor axis. J Anim Sci 77, 2934-2941.

Howells KF, Mathews DR \& Jordan TC (1978) Effects of preand perinatal malnutrition on muscle fibres from fast and slow rat muscles. Res Exp Med 173, 35-40.

Kelley RL, Jungst SB, Spencer TE, Owsley WF, Rahe CH \& Mulvaney DR (1995) Maternal treatment with growth hormone alters embryonic development and early postnatal growth of pigs. Domest Anim Endocrinol 12, 83-94.

Kind KL, Owens JA \& Robinson JS, et al. (1995) Effect of restriction of placental growth on expression of IGFs in fetal sheep: relationship to fetal growth, circulating IGFs and binding proteins. J Endocrinol 146, 23-34.

Kirkwood RN, Peacock AJ \& Thacker PA (1993) The influence of growth hormone injections either pre- or post-breeding on the reproductive performance of sows and gilts. Can J Anim Sci 73, 259-265.

Klindt J, Buonomo FC, Yen JT, Pond WG \& Mersmann HJ (1995) Administration of porcine somatotropin by daily injection: growth and endocrine responses in genetically lean and obese barrows and gilts. J Anim Sci 73, 3294-3303.

Kveragas CL, Seerley RW, Martin RJ \& Vandergrift WL (1986) Influence of exogenous growth hormone and gestational diet on sow blood and milk characteristics and on baby pig blood, body composition and performance. J Anim Sci 63, 1877-1887. 
Lok F, Owens JA, Mundy L, Robinson JS \& Owens PC (1996) Insulin-like growth factor I promotes growth selectively in fetal sheep in late gestation. Am J Physiol 270, R1148-R1155.

Lucas A (1991) Programming by early nutrition in man. In The Childhood Environment and Adult Disease, pp. 38-55 [GR Bock and J Whelan, editors]. Chichester, Sussex: Wiley.

Martorell R, Stein AD \& Schroeder DG (2001) Early nutrition and later adiposity. $J$ Nutr 131, 874S-880S.

National Health and Medical Research Council of Australia (1997) Australian Code of Practice for the Care and Use of Animals for Scientific Purposes, 6th ed., Canberra: Australian Government Publishing Service.

Owens JA, Kind KL, Carbone F, Robinson JS \& Owens PC (1994) Circulating insulin-like growth factors-I and -II and substrates in fetal sheep following restriction of placental growth. $J$ Endocrinol 140, 5-13.

Owens PC, Conlon MA, Campbell RG, Johnson RJ, King R \& Ballard FJ (1991) Developmental changes in growth hormone, insulin-like growth factors (IGF-I and IGF-II) and IGF-binding proteins in plasma of young growing pigs. $J$ Endocrinol $\mathbf{1 2 8}$, 439-447.

Owens PC, Johnson RJ, Campbell RG \& Ballard FJ (1990) Growth hormone increases insulin-like growth factor-I (IGF-I) and decreases IGF-II in plasma of growing pigs. $J$ Endocrinol 124, 269-275.

Palmer RM, Thompson MG, Meallet C, Thom A, Aitken RP \& Wallace JM (1998) Growth and metabolism of fetal and maternal muscles of adolescent sheep on high or adequate feed intakes: possible role of protein kinase $\mathrm{C}-\alpha$ in fetal muscle growth. Brit J Nutr 79, 351-357.

Rehfeldt C, Fiedler I, Weikard R, Kanitz E \& Ender K (1993) It is possible to increase skeletal muscle fibre number in utero. Biosci Rep 13, 213-220.
Rehfeldt C, Kuhn G \& Kanitz E, et al. (1996) Fetal growth and skeletal muscle development in response to somatotropin treatment during early gestation. J Anim Sci 74, Suppl. 1, 142, Abstr.

Roberts CT, Sohlstrom A \& Kind KL, et al. (2001) Altered placental structure induced by maternal food restriction in the guinea pig: a role for IGF-II and IGFBP-2 in the mother. Placenta 22, S77-S88.

Sohlstrom A, Fernberg P, Owens JA \& Owens PC (2001) Maternal nutrition affects the ability of treatment with IGF-I and IGF-II to increase growth of the placenta and fetus in guinea pigs. Growth Horm IGF Res 11, 392-398.

Spencer GSG, Robinson GM, Berry CJ \& Dobbie PM (1994) Alteration of maternal growth hormone levels during pregnancy influences both fetal and postnatal growth in rats. Bio Neonat 66, 112-118.

Sterle JA, Cantley TC \& Lamberson WB, et al. (1995) Effects of recombinant porcine growth hormone on placental size, fetal growth, and IGF-I and IGF-II concentrations in pigs. J Anim Sci 73, 2980-2985.

Wallace JM, Aitken RP \& Cheyne MA (1996) Nutrient partitioning and fetal growth in rapidly growing adolescent ewes. $J$ Reprod Fertil 107, 183-190.

Walton PE \& Etherton TD (1986) Stimulation of lipogenesis by insulin in swine adipose tissue: Antagonism by porcine growth hormone. J Anim Sci 62, 1584-1595.

Ward SS \& Stickland NC (1991) Why are slow and fast muscles differentially affected during prenatal undernutrition? Muscle Nerve 14, 259-267.

Wigmore PMC \& Stickland NC (1983) Muscle development in large and small pig fetuses. J Anat 137, 235-245.

Wilson SJ, Ross JJ \& Harris AJ (1988) A critical period for formation of secondary myotubes defined by prenatal undernourishment in rats. Development 102, 815-821. 